\title{
Utilization of Linguistic Aspects of Bloom's Taxonomy in Blended Learning
}

\author{
Marcel Pikhart*(D) and Blanka Klimova \\ Department of Applied Linguistics, University of Hradec Kralove, 50003 Hradec Kralove, Czech Republic \\ * Correspondence: marcel.pikhart@uhk.cz
}

Received: 5 August 2019; Accepted: 4 September 2019; Published: 9 September 2019

\begin{abstract}
This paper presents findings from the practical implementation of Bloom's taxonomy into the class of Intercultural Business Communication that has been taught for several years at the Faculty of Informatics and Management, University of Hradec Kralove, Czech Republic. The class utilizes blended learning, and recently, Bloom's taxonomy has been introduced into the online course. Research I tests the students' satisfaction with the class before introducing Bloom's taxonomy, and Research II tests the students' satisfaction with the new approach using the Bloom's taxonomy. The findings are as follows: the students realized the difference after the implementation of Bloom's taxonomy into the online course; moreover, the students also evaluated the new course in a much more positive way than the previous one. Bloom's taxonomy, therefore, proved to be enormously useful in this blended learning environment, and the present paper highlights the importance of such an implementation. As a consequence, blended learning courses using Bloom's taxonomy will be more systematic and therefore more efficient. The results of this research show that proper linguistic utilization of Bloom's taxonomy terminology proved to be useful, and the paper stresses the importance of systematic approaches in blended learning courses so that they are creative and attractive for the new generation of online course users. Considering the small number of participants, further studies are needed to confirm the results of this research.
\end{abstract}

Keywords: blended learning; intercultural communication courses; eLearning; linguistic aspects of blended learning; hybrid learning; communication

\section{Introduction}

\subsection{Literature Review}

Blended learning as a standard methodology combining traditional approaches to the learning process with online learning [1] has already been established as a varied and very efficient tool of learning using modern electronic tools and media. The modern world, which can be described by interconnectedness, multiculturality, global communication, and large scale networks, brings new challenges as well as means of communication and learning methodologies [2,3].

Blended learning has proved to be one of the most useful learning strategies; however, students who are daily users of new technologies tend to lack initial fervor and interest when using electronic devices in their learning process [4,5]. Motivating students using electronic tools is therefore one of the most important tasks if blended learning is to become successful and fruitful [6-9]. Motivating users by using traditional tools has already failed, and the creators of these traditional courses must find new ways how to attract the attention of users and retain it for a sufficient amount of time [10,11].

Basic observation of the users of online courses shows that they lack initial interest due to their everyday contact with and use of these devices, which could be termed as "electronic device use fatigue." When creating online courses, which are a necessary part of any blended learning, we must 
find new ways to motivate and attract users, so that the courses will be efficient in terms of students' learning progress and outcomes [12-14].

The new generation of blended learning users will be different from the previous one. The students will be more skeptical to the use of traditional approaches, which will have to be transferred into more systematic methodologies and well-structured courses. The users will demand clear and achievable goals demonstrated in blended learning classes, and all these aspects will be crucial to the success of any online course presented to them [15-18].

Blended learning has established its strong position among modern learning processes; however, it is crucial to draw attention to possible drawbacks that may appear in the course of time. Increasingly more users of blended learning show their lack of interest in and inspiration from online learning environments for many reasons [19-22].

One of the most important reasons is the amount of time that students spend using mobile and other electronic devices, which are the core and basis of blended learning. Scarce research has investigated these drawbacks and limitations; however, these must be seriously taken into account, otherwise they will create a serious threat for any progress in blended learning educational processes. This aspect is, however, still rather neglected in the literature, and this paper attempts to highlight its importance.

On the other hand, these drawbacks are well balanced with the enormous advantages of blended learning, and it would be a grave mistake not to take them into consideration, as they create a negative environment, which is not desired in the learning process [23-25]. Blended learning has a great chance to succeed in the global transfer of information, global learning processes, and global interconnectedness of its users. The creators of blended learning courses will have to use this opportunity to influence the new generation of users of online courses, so that this great teaching and learning opportunity in the global world can be fully enjoyed [22,26].

The drawbacks of blended learning are only virtual, that is, if we adapt to the new trends and main demands of the users of these courses, we can succeed, and our learning outcomes will be better and more competitive in the global learning environment [27]. By being able to cope with the new challenges in blended learning, we will also make our learning centers more global, and their global presence will be more visible and successful $[28,29]$.

Bloom's methodology has already drawn some attention from scholars who are interested in e-learning; however, none of their research focused on the linguistic aspect of Bloom's taxonomy. The need for clarification when giving instructions is mentioned by Gaitanaru [30] or Ku et al. [31], reporting rapid e-learning tools also utilizing some aspects of Bloom's taxonomy. Jagzape et al. [32] observed how involving cognitive domain in online courses endorsed communication and improved students' concepts. A basic introduction to Bloom's taxonomy describing its usefulness in creating more congruence among the components of online instructions is provided by Chyung et al. [33].

\subsection{Bloom's Taxonomy in Pedagogy}

Bloom's taxonomy has been used in pedagogy as a useful tool to create clear structure, vision, and learning process parameters on which any course can be built and developed [34,35]. There are two methodologies, namely, the original Bloom's taxonomy from 1956, which was a breakthrough in the pedagogy and psychology of learning, and the revised one from 2001, which refined the original terminology and introduced a few new concepts, but retained the core principles of the original taxonomy. The specific tools used in Bloom's taxonomy can be utilized in any kind of instructions in the learning process; however, the authors of the present paper feel the taxonomy can be very useful when using digital media, i.e., in online and blended learning. Previous research shows $[16,36]$ that the clarity of instructions and transfer of information in the digital era has deteriorated; therefore, it can be very useful to refresh and implement Bloom's taxonomy.

Bloom's taxonomy simply distinguishes six steps in the learning process, which are achievable through the process of education, and attainable while going through the course. 
The basic levels of acquired skills and competencies are:

1. Remember-recalling facts, information, and basic ideas memorized by heart; this is just plain memorizing and learning by heart without any creative approach or specific performance, yet important and useful at very early stages of the learning process

2. Understand-being able to explain to others the idea that has been remembered, in the form of a presentation or any other means that will prove that the student understands the idea

3. Apply_-being able to use the acquired information in new contexts and situations and transferring it into everyday life; this means transferring acquired ideas into a practical context, bringing them into life and usage

4. Analyze-creating connections and trying to compare and contrast them with each other; analyzing means being able to find connections and causal relationships in reportedly disconnected items

5. Evaluate-developing a more creative approach while being able to appraise and defend one's own opinions and ideas; evaluation creates a very high level of understanding and mental skills by being able to defend the ideas acquired in the learning process

6. Create-highest level, means being able to produce a new idea based on the items already learned; creativity is the highest achievable goal that proves that the student has reached independence.

All these six skills are necessary in the learning process; however, they create a naturally developing sequence starting from number one as the easiest, to number six, which is the most complicated but also most desired. They all, to differing extents, in various volumes and widths, are present in any learning process; however, Bloom's taxonomy helps us to deliberately use them with a rather more systematic approach to the blended learning process and online course creation.

\subsection{Bloom's Taxonomy in Blended Learning}

Using Bloom's taxonomy in online courses of blended learning is relatively simple, as users can apply several key terms to their syllabi and online courses as well. The following list provides practical uses of these verbs that could be implemented. The list is merely introductory; however, it presents all the basic approaches to Bloom's taxonomy applied to blended learning, and this approach was also used in the creation of the course examined in this paper, i.e., Intercultural Business Communication at the Faculty of Informatics and Management of the University of Hradec Kralove.

Using specific terminology while creating online courses guided by Bloom's taxonomy will prove that linguistic aspects are crucial in the global world, which increasingly relies on word and iconic information - the Internet is the most powerful tool that is based on this phenomenon. Words are the tools that form the basis of Bloom's taxonomy, and their proper and adequate use will help us to create more efficient means for online communication, which will thus become more precise and organized.

Table 1 clearly outlines the basic verbs, which are divided into categories connected to the given taxonomy above, i.e., the means by which the skills and competencies can be easily described and presented. This is also an aspect of commodification of linguistic scenarios, that is, linguistic phenomena become a utilitarian issue, which must be considered while creating any online course that aims to be successful and influential in the global world.

Table 1. Adapted from Reference [33].

\begin{tabular}{ll}
\hline Skills and Competencies & \multicolumn{1}{c}{ Verbs to Be Used } \\
\hline Remember & Define, duplicate, list, memorize, repeat, write \\
Understand & Describe, discuss, explain, identify, locate, recognize, report, select \\
Apply & Implement, solve, use, demonstrate, interpret, operate \\
Analyze & Differentiate, organize, relate, compare, contrast, distinguish, examine, test \\
Evaluate & Appraise, argue, defend, judge, select, support, value, weigh \\
Create & Design, assemble, construct, develop, formulate, investigate \\
\hline
\end{tabular}


The list of these verbs does not contain all the verbs that could be used; however, it can work as a preliminary tool for the creators of online courses to realize the importance of the various tasks and their exact description. Bloom's taxonomy can therefore be used in a variety of contexts; however, in blended learning courses, it proves to be enormously useful and productive because online course users can clearly see their skills achieved and progress towards them.

\section{Materials and Methods}

\subsection{Research Questions and Aims}

The research questions were as follows:

1. How successful will be Bloom's taxonomy applied to the blended learning course of Intercultural Business Communication?

2. What benefits will the use of Bloom's taxonomy bring for the creator of the blended learning course?

3. What benefits will the use of Bloom's taxonomy bring for the users of the blended learning course?

The research aim was to verify if the utilization of the Bloom's taxonomy in blended learning can potentially bring significant improvement of the course of Intercultural Business Communication.

\subsection{Research Methodology}

This research was based on standard methodology of quantitative research, with the following parameters and criteria. The research was conducted at the Faculty of Informatics and Management of the University of Hradec Kralove, Czech Republic, in the winter semester of the academic year 2018/2019. Research I was conducted at the beginning of the semester-the online course was held before the implementation of Bloom's taxonomy. Research II was conducted in the second half of the semester-Bloom's taxonomy was implemented into the online course. The basic principles of Bloom's taxonomy were implemented based on the authoritative sources [33,34].

The respondents were international students of Finance Management and Information Management of the Faculty of Information Technology and Management of the University of Hradec Kralove. The total number of respondents was 56, both male and female, aged between 20 and 25 . Respondents came from Czech Republic, Mexico, Taiwan, China, Japan, Turkey, Spain, Italy, France, Slovakia, Romania, Bulgaria, Kazakhstan, Belarus, and Bolivia. The national variety was enormous and greatly helped to provide diversity and a more concentrated focus to the research.

The author of the paper introduced blended learning into his course of Intercultural Business Communication (which lasts 13 weeks, with two 45-min lessons each week including lectures and seminars supplemented with online courses) shortly after a few weeks into the semester. This is a theoretical and practical communication course for the students of business, finance, and Information and communication technology. It focuses on intercultural issues of business communication in the global business world, how communication is performed through modern communication channels, and how it could be optimized.

Blended learning is performed using the Blackboard tool, the Internet, and various other platforms, mostly to communicate with the students, evaluate them, and also to conduct research through online questionnaires with both open-ended and yes-no questions. The respondents were asked specific questions about their satisfaction with the use of electronic means (mostly the Blackboard platform) during the course.

The tutor introduced Bloom's taxonomy into the course during the semester, and the respondents had to answer the same questionnaire again after this implementation. The respondents were asked through an online questionnaire, and the results collected and processed using standardized methodology for quantitative data collection and processing. For data analysis, confirmatory data analysis was used to find out the answers to the research questions, and simple SMART methodology 
by Peter Drucker from project management was used, as it provides a simple tool to set or measure objectives [36].

At the beginning, the course was created using the standard methodology to create online courses in European universities, which follows the European Credit Transfer System, i.e., there are basic templates for the courses that can be modified based on the instructor. However, the instructor of the course tried to intentionally implement Bloom's taxonomy in the middle of the course to test the reaction of the users and their satisfaction. There are certain limitations to this research; however, it still brings new ideas and very pragmatic findings regarding the use of Bloom's taxonomy in online courses of blended learning.

\section{Results and Discussion}

The immediate findings of the research were very positive in favor of Bloom's taxonomy used in the online course. After its implementation, the respondents clearly showed their enhanced satisfaction with the clear structure and clearly defined aims corresponding to the previous introduction of Bloom's taxonomy.

The results from Research I helped the tutor to upgrade the course using Bloom's taxonomy during the semester, so that subsequent Research II could be conducted. The results of Research I and II make sense in their comparison, rather than as isolated entities, as the comparison shows a causal connection between the two versions of the online course.

When comparing Research I and II, it is clearly visible that the respondents showed their immediate satisfaction after the implementation. The reason for this dramatic change was the implementation of clearly defined tasks and aims in line with Bloom's taxonomy methodology.

Research I showed $67 \%$ of overall satisfaction with the online course; however, Research II, after the implementation of Bloom's taxonomy, showed $87 \%$ of overall satisfaction with the course (Table 2). The respondents clearly demonstrated their interest in the course when the tasks were clearly stated and the outcomes of individual tasks highlighted. The respondents also highlighted the importance of clearly defined tasks that were evaluated by using the SMART methodology (specific-measurable-achievable-realistic-time-specific, corresponding to questions 4-8 in the questionnaire). Bloom's taxonomy helps with clear definition of tasks and their outcomes, and with evaluation of the learning process and results.

Table 2. Research I and II results.

\begin{tabular}{llc}
\hline \multicolumn{1}{c}{ Items } & Research I & Research II \\
\hline 1. Sufficient clarity of the instructions of the course & $42 \%$ & $86 \%$ \\
2. Sufficient description of the tasks & $56 \%$ & $76 \%$ \\
3. Satisfaction with the description of the objectives & $43 \%$ & $83 \%$ \\
4. Are the tasks specific? & $46 \%$ & $74 \%$ \\
5. Are the tasks measurable? & $35 \%$ & $37 \%$ \\
6. Are the tasks achievable? & $56 \%$ & $61 \%$ \\
7. Are the tasks realistic? & $58 \%$ & $59 \%$ \\
8. Are the tasks time-specific? & $64 \%$ & $67 \%$ \\
9. Overall satisfaction with the online course & $67 \%$ & $87 \%$ \\
\hline
\end{tabular}

Research I results also show that the respondents lacked clearly formulated tasks, and Research II results suggest that this feature was eliminated or at least minimized. The difference between Research I and II was so visible that it can be concluded that the only reason for this must be objective- the change in the structure and methodology of the online course. External influences can be eliminated as the respondents were identical in Research I and II. Additionally, the sequence of Research I and II was also very quick, i.e., Research II was conducted just a few weeks after Research I.

The previous table (Table 2) shows the percentage of positive answers as a summary of the most important findings of the questionnaire. The following questions were asked: 
1. Are the instructions given in the course clear?

2. Is the description of the tasks straightforward and easy to understand?

3. Are you satisfied with the description of the objectives of the course?

4. Are the given tasks specific enough for you?

5. Is the result of the task and your performance objectively measurable?

6. Is it difficult to achieve the task? Or too complicated?

7. Are the tasks and deadlines realistic for you?

8. Are the given deadlines specific enough?

9. What is your overall satisfaction with the course?

In none of the tested parameters can we observe a drop, i.e., after the implementation of Bloom's taxonomy, each particular tested parameter improved, either significantly or at least marginally. The implementation of Bloom's taxonomy itself into the online course of Intercultural Business Communication proved to be helpful not only for the users of the course but for the creator as well. It enables the course to be clearly structured, and the format of the individual tasks always takes into account the goals that should be achieved. When comparing with traditional approaches in online courses and blended learning, we can observe a much higher subjective satisfaction [1,19]. It is crucial that user satisfaction with the given online course increases, as this satisfaction is crucial for the further and repeated use of the app or online course [5,14].

The answer to research question 3 (i.e., the benefits of the Bloom's taxonomy for the users) is as follows: The users of the course will have a feeling that they are guided in a well-structured manner and that their guide knows the journey very well. When students go from the remembering to the understanding phase (i.e., able to explain ideas and concepts), they feel they have already attained a particular milestone in their learning process. Moreover, applying the ideas learned and their analysis proves to be helpful in getting a solid background while learning new ideas and developing skills and competencies. Being able to evaluate this knowledge further will naturally lead to being able to generate new values and ideas. Again, a lot of research proves the increase in creativity among users of blended learning courses if they are created adequately and when they take into consideration all the needs of participants in these courses [8].

Using Bloom's taxonomy while creating similar online courses is a very useful tool to increase success in the global learning environment, and the respondents unanimously expressed their satisfaction, as this research clearly shows. Blended learning on its own must not become obsolete-we must be aware that even if it uses modern technology, it can easily become old-fashioned and unattractive. Bloom's taxonomy is a useful tool to create blended learning courses that will not lack interest and attractiveness, which gives us the answer to research question 2. Course creators will be equipped with a linguistic tool that can help them to formulate instructions clearly when creating an online course.

To conclude, the utilization of Bloom's taxonomy improved students' satisfaction with the online course dramatically, and it was only the linguistic change in the course that made the dramatic difference, as there was no change to the contents or structure of the course.

\section{Research Limitations}

The research has, obviously, several limitations which should be taken into account and can also be used as inspiration for further research. The number of respondents was restricted to a few dozens; however, they were a representative sample. The respondents were biased by Research I, as Research II could have been influenced by this. Further research is needed to test the usability and usefulness of Bloom's taxonomy at a larger scale and in more detail, so that these preliminary findings can be confirmed by a double-check with another group of respondents. 


\section{Conclusions}

The paper is an attempt to use a relatively easy methodology in the creation of online courses, i.e., Bloom's taxonomy, which is easily applicable and implementable into online university curricula. Any online course using this methodology will be clearly structured and in accordance with SMART methodology, which will make the learning process easier and the results more easily achievable. The present research clearly shows the connection between Bloom's taxonomy and the satisfaction with the online course. Despite the fact that Bloom's taxonomy may seem old-fashioned and not appropriate for modern online courses, it proved to be extremely helpful and highly increased students' satisfaction, which could eventually lead to better outcomes and success in their learning process. Moreover, simply the improved satisfaction and clarity of the tasks will necessarily lead to better performance and results.

The global world of interconnectedness and cooperation needs creative individuals, and the present paper attempts to show that Bloom's taxonomy is a very useful tool when used in online courses that increases creativity. Bloom's taxonomy will prove useful for both creators and users of blended learning methodology, as it creates well-structured and clearly formulated tasks, and provides clear objectives and achievable goals in the chaos of the global world and Internet cyberspace.

All the challenges of the modern world and the new generation of students generate a need for new approaches to communication and teaching; this is the only way to succeed as educators. Creating online courses and blended learning that is based on firm foundations is essential to be competitive and successful. Bloom's taxonomy could seem a very old-fashioned tool and its implementation in modern online courses and other electronic tools for communication could appear obsolete; however, this paper briefly shows that it is a powerful tool that elegantly connects modern information media with traditional and well-established pedagogical tools.

Author Contributions: Conceptualization M.P.; methodology B.K.; investigation M.P., B.K.; resources B.K.; writing—original draft preparation M.P., B.K.; writing—review and editing M.P.; supervision B.K.

Funding: This research received no external funding.

Acknowledgments: The paper is part of the SPEV 2019 project run at the Faculty of Informatics and Management, University of Hradec Kralove. The authors would like to thank Ales Berger for his help when preparing the manuscript.

Conflicts of Interest: The authors declare no conflict of interest.

\section{References}

1. Bazelais, P.; Doleck, T. Blended learning and traditional learning: A comparative study of college mechanics courses. Educ. Inf. Tech. 2018, 23, 2889-2900. [CrossRef]

2. Pikhart, M. Implementing new global business trends to intercultural business communication. Procedia Soc. Behav. Sci. 2014, 152, 954-957. [CrossRef]

3. Pikhart, M. New Horizons of intercultural communication: Applied linguistics approach. In Proceedings of the ERPA International Congress on Education, Amsterdam, The Netherlands; 2014; pp. 954-957.

4. El-Hmoudova, D. The value of intelligent multimedia application in applied linguistics instruction. Adv. Sci. Lett. 2018, 24, 2546-2549. [CrossRef]

5. Klimova, B. Smart teacher. Smart education and E-learning 2017. In Proceedings of the SEEL 2017, Algarve, Portugal, 21-23 June 2018; pp. 321-328.

6. Ashmarina, S.; Kandrashina, E.; Zotova, A. Global educational trends in intellectual capital development. In Proceedings of the Innovative Economic Symposium (IES2017): Strategic Partnership in International Trade, SHS Web of Conferences, Ceske Budejovice, Czech Republic, 19 October 2017.

7. Pikhart, M. Intercultural linguistics as a new academic approach to communication. In Proceedings of the ERPA International Congress on Education, Athens, Greece, 4-7 June 2015.

8. Berger, A.; Klímová, B. Mobile application for the teaching of English. Lect. Notes Electr. Eng. 2019, 518, 1-6. 
9. Artal-Sevil, J.S.; Romero-Pascual, E.; Artacho-Terrer, M.J. Blended-learning: New trends and experiences in higher education. In Proceedings of the 8th International Conference of Education, Research and Innovation, Sevilla, Spain, 18-20 November 2015; pp. 7761-7771.

10. Vaculikova, J. Modern technology and internet use in learning in the Czech Population. In Proceedings of the 21st International Business Information Management Association Conference, Vienna, Austria, 27-28 June 2013; pp. 160-172.

11. Cerna, M.; Svobodova, L. Internet and social networks as a support for communication in the business environment-pilot study. Hradec Econ. Days 2017, 7, 120-126.

12. El-Hmoudova, D.; Loudova, I. Implementation of Assessment for Learning (AfL) in Blackboard LMS and Its Reflection on Tertiary Students' Second Language Performance; Springer: Cham, Switzerland, 2018. [CrossRef]

13. Sclater, M. Sustainability and learning: Aesthetic and creative responses in a digital culture. Res. Comp. Int. Educ. 2018, 13, 135-151. [CrossRef]

14. Klimova, B.; Poulova, P. Older people and technology acceptance. Lect. Notes Comput. Sci. 2018, 10926, 85-94.

15. Pikhart, M. Multilingual and intercultural competence for ICT: Accessing and assessing electronic information in the global world. Adv. Intell. Syst. Comput. 2019, 833, 273-278.

16. Sikora, Y.B. The use of knowledge management methods for e-learning organization. Inf. Tech. Learn. Tools 2017, 61, 162-174.

17. Vranes, A.; Markovic, Lj.; Mariokov, M.J. Enhancing language, literature and culture teaching and learning throughout ICTS implementation. In Proceedings of the 10th International Technology, Education and Development Conference (INTED), Valencia, Spain, 7-9 March 2016; pp. 2533-2540.

18. El-Hmoudova, D. CB Language competences testing methods in the class of tourism management. In Proceedings of the ERPA International Congresses on Education (ERPA 2017), Budapest, Hungary, 18-21 May 2017; pp. 1-7.

19. Klimova, B. Assessment in the eLearning course on academic writing-A case study. Lect. Notes Comput. Sci. 2017, 10108, 733-738.

20. Klimova, B.; Poulova, P. Mobile learning and its potential for engineering education. In Proceedings of the IEEE Global Engineering Education Conference (EDUCON), Tallinn, Estonia, 18-20 March 2015; pp. 47-51.

21. Ramirez-Arellano, A.; Acosta-Gonzaga, E.; Bory-Reyes, J. Factors affecting student learning performance: A causal model in higher blended education. J. Comput. Assist. Learn. 2018, 34, 807-815. [CrossRef]

22. Banks, J.; Cheng, J.; Payne, S. Fostering a technologically innovative teaching culture. In Proceedings of the 1st International Conference on Higher Education Advances, Valencia, Spain, 24-26 June 2015; pp. 225-232.

23. Stofkova, J.; Stofko, S.; Loucanova, E. Possibilities of using E-learning system of education at universities. In Proceedings of the 11th International Technology, Education and Development Conference, Valencia, Spain, 5-8 March 2017; pp. 6965-6972.

24. Teodorescu, A. Mobile learning and its impact on business English learning. Procedia Soc. Behav. Sci. 2015, 180, 1534-1540. [CrossRef]

25. Langset, I.D.; Jacobsen, D.Y.; Haugsbakken, H. Digital professional development: Towards a collaborative learning approach for taking higher education into the digitalized age. Nord. J. Digit. Lit. 2015, 13, $24-39$. [CrossRef]

26. Yang, J. Mobile assisted language learning: Review of the recent applications of emerging mobile technologies. Eng. Lang. Teach. 2013, 6, 19-25. [CrossRef]

27. Sun, J. Convergence and divergence in blended learning. In Proceedings of the 9th International Conference on Blended Learning (ICBL), Beijing, China, 19-21 July 2016; pp. 292-301.

28. Welzer, T.; Druzovec, M.; Kamisalici, A. Cultural aspects in technology-enhanced education. In Proceedings of the World Congress on Medical Physics and Biomedical Engineering, Prague, Czech Republic, 3-8 June 2018; pp. 885-888.

29. Gaitanaru, A. Ontology and taxonomies for elearning. Euromentor J. 2016, 7, 62.

30. Ku, D.T.; Yung-Hsin, H. The Development of procedure and design principle of using rapid e-learning tools in Bloom's taxonomy. J. Educ. Media Libr. Sci. 2011, 48, 511-538.

31. Jagzape, A.T.; Kamal, S.; Kirti, P. Group-based asynchronous e-learning incorporating revised Bloom's taxonomy: An innovative approach. J. Clin. Diagn. Res. 2018, 12, JC01-JC06. [CrossRef] 
32. Chyung, S.Y.; Stepich, D. Applying the "congruence" principle of Bloom's taxonomy to Designing online instruction. Q. Rev. Distance Educ. 2003, 4, 317.

33. Bloom, B.; Engelhart, M.; Furst, E.; Hill, W.; Krathwohl, D. Taxonomy of Educational Objectives. The Classification of Educational Goals; Longmans: London, UK, 1956.

34. A Taxonomy for Learning, Teaching, and Assessing: A Revision of Bloom's Taxonomy of Educational Objectives; Anderson, L.W.; Krathwohl, D.R. (Eds.) Addison Wesley Longman, Inc: New York, NY, USA, 2001.

35. Pikhart, M. Technology enhanced learning experience in intercultural business communication course: A case study. Lect. Notes Comput. Sci. 2018, 11284, 41-45.

36. Drucker, P.F. Management Challenges for the 21st Century; Routledge: Abingdon, UK, 2007; ISBN $978-0887309991$.

(C) 2019 by the authors. Licensee MDPI, Basel, Switzerland. This article is an open access article distributed under the terms and conditions of the Creative Commons Attribution (CC BY) license (http://creativecommons.org/licenses/by/4.0/). 